School of Finance

University of St.Gallen

Has Crude Oil Become a Financial Asset?

EVIDENCE FROM TEN YEARS OF FINANCIALIZATION

ZENO ADAMS

MARIA KARTSAKLI

WORKING PAPERS ON FINANCE No. 2017/10

SWISS INSTITUTE OF BANKING AND FINANCE (S/BF - HSG)

FEBRUARY 2017 


\title{
Has Crude Oil Become a Financial Asset? Evidence from Ten Years of Financialization*
}

\author{
Maria Kartsakli ${ }^{\ddagger}$ and Zeno Adams ${ }^{\S}$
}

Working Paper

This version: February 2017

\footnotetext{
* We would like to thank Ulrike Grömping, Elli Kartsakli, and Cynthia Wu for valuable comments and suggestions. We also thank Richard Papp for invaluable research assistance. This work is supported by GFF fund no. 2130882.

$\$$ Swiss Institute of Banking and Finance (s/bf), University of St.Gallen, Unterer Graben 21, 9000 St. Gallen, Switzerland, Phone: +41 (0)71 224 7755, Fax: +41 (0)71 224 7088, Email: maria.kartsakli@unisg.ch.

${ }^{\S}$ Swiss Institute of Banking and Finance (s/bf), University of St.Gallen, Unterer Graben 21, 9000 St. Gallen, Switzerland, Phone: +41 (0)71 224 7057, Fax: +41 (0)71 224 7088, Email: zeno.adams@unisg.ch.
} 


\title{
Has Crude Oil Become a Financial Asset? Evidence from Ten Years of Financialization
}

\begin{abstract}
The financialization of crude oil markets over the last decade has changed the behavior of oil prices in fundamental ways. In this paper, we uncover the gradual transformation of crude oil from a physical to a financial asset. Although economic demand and supply factors continue to play an important role, recent indicators associated with financialization have emerged since 2008. We show that financial variables have become the main driving factors explaining the variation in crude oil returns and volatility today. Our findings have important implications for portfolio analysis and for the effectiveness of hedging in crude oil markets.
\end{abstract}

Keywords: $\quad$ Crude oil; financialization; $R$-squared decomposition

JEL-Classification: $\quad Q 40, Q 41, G 14$ 


\section{Introduction}

Like most other commodities, crude oil is considered a real asset. Prices are determined by the demand for refined products and production rates of oil suppliers. A long position in a crude oil futures contract is a bet on rising oil prices that is disconnected from the physical world. The large majority of crude oil futures are closed prior to maturity so that trading in futures does not affect the price of physical crude oil. This is the traditional view of segmented commodity futures and spot markets.

This view has been challenged by recent events that are caused by the increased presence of financial investors in commodity markets. The phenomenon is known as the financialization of commodity markets and is estimated to have emerged around 2004 when inflows into commodity markets increased from \$ 15 billion to over \$ 250 billion in 2009 (Irwin and Sanders, 2011, Tang and Xiong, 2012). There has been considerable effort in the recent academic literature to measure and quantify financialization and to investigate the implications for markets and investors. Broadly defined, the literature has identified two areas that underwent significant changes since 2004. The most visible change is perhaps the dramatic increase in comovement, both within the commodity universe (Tang and Xiong, 2012), and with the general stock market (Cheng and Xiong, 2014). The second change occurred in the returns and the volatility of commodity spot prices. In particular, financialization and large scale speculation in commodity futures markets appears to have significant spillover effects on the prices of physical commodities. The link between speculation and physical prices is a controversial issue. In a recent literature review, Haase et al. (2016) examine 100 papers that have been published on the topic of financialization in commodity markets over the last decade. The authors conclude that the number of papers finding a positive effect of speculation and the ones finding a negative effect are about the same. The overall picture is therefore rather mixed. The contradicting findings seem to be the result of poorly designed empirical models and a lack of high quality data. In particular, direct measures of financial investor positions cannot offer a clear distinction between hedgers, arbitrageurs, and speculators. This data problem lies in the very nature of market participants who tend to engage in several activities over time (Cheng and Xiong, 2014). ${ }^{1}$ When it comes to model design, many empirical studies suffer from endogeneity that arises between commodity futures prices and the net long positions of financial

\footnotetext{
${ }^{1}$ Another source of confusion appears to be a lack of high quality inventory data. The inability to distinguish between inventory demand coming from commodity consumers and producers weakens the significance of studies focusing on inventory data.
} 
investors. Finally, the topic is heavily politicized with industry interests likely to prevent a consensus in the near future.

A second generation of empirical studies is more careful in their empirical design and address the endogeneity issue appropriately by measuring the exogenous variations in financial investor's futures positions. ${ }^{2}$ The recent findings in this literature show a clear link between financialization and commodity markets, and our own view is that commodity price dynamics are difficult to explain by economic supply and demand alone. However, existing studies try to answer the question whether different aspects of financialization can have an impact on commodity markets. The tendency is to take a partial view of the market were some shock has a statistically significant impact on prices, returns, or commodity volatility. We want go a step further and try to quantify the extent to which the last 10 years of financialization have changed the commodity landscape. Given our existing knowledge about the effects of financialization, the main question is no longer whether financialization can affect commodity markets, but rather whether we should start thinking of commodities as financial rather than physical assets.

In this paper, we aim to answer this question using fundamental economic variables that have been the traditional drivers of commodities, as well as more recent variables that have been associated with financialization. Our empirical strategy is based on a simple idea: if financial variables have recently become more relevant than economic variables we should expect financial variables to be better at explaining the variation of commodity prices over time than fundamental economic factors. Following this idea, we evaluate the contribution of each factor to the R-squared of a rolling window regression. Focusing on the R-squared and its decomposition, rather than the regression coefficients, has a number of advantages. First, the coefficient estimates are generally not useful for answering the question whether a variable is important for explaining crude oil price changes. For instance, a key variable in our empirical setup is a measure of macroeconomic uncertainty. In a regression of oil volatility on macroeconomic uncertainty and control variables we find that the uncertainty coefficient is estimated to be 45 in the pre-financialization period and 23 in the following financialization period. Both estimates are statistically significant. From these coefficient estimates one could conclude that macroeconomic uncertainty has become less important for explaining the variation in crude oil volatility. The R-squared decomposition that we apply in our analysis

${ }^{2}$ Two papers that stand out for their strong empirical identification are Cheng, Kirilenko, and Xiong (2015) who circumvent the endogeneity problem by focusing on risk rather than prices, and Henderson, Pearson, and Wang (2015) who use data on exogenous investment flows of commodity-linked notes. 
however shows that macroeconomic uncertainty is not less important but more important during the financialization period. Macroeconomic uncertainty today explains a much larger proportion of the time variation in crude oil volatility than in previous years. Our methodological approach therefore has a number of advantages over standard regression tables.

A side effect of our approach is that it allows for the presence of endogeneity. For instance, the commodity risk premium that reflects the trading demand of financial investors not only affects commodity prices, but commodity prices also attract investors into the market in turn affecting the risk premium. While the presence of endogeneity prevents us from estimating the causal effect, we can measure the contribution of the interaction between risk premium and prices on the R-squared of the regression model. Since we rely on variables that other studies have already shown to be important for commodity price dynamics, we can build our analysis on the R-squared decomposition without the need for causality. The result is an intuitive and direct interpretation of the importance of traditional economic variables on the one hand, and financialization indicators on the other. The outcome variables of interest are crude oil prices, oil returns, and the volatility of oil returns. Our main finding is that economic fundamental variables continue to play an important role but that the influence of financial variables has dramatically increased over time. Our empirical results indicate that since the beginning of the financialization period, financial variables explain $35 \%$ of the variation in crude oil returns while their influence was only $11 \%$ during pre-financialization years. More importantly, financial variables can currently explain the majority of the variation in crude oil volatility (53\%), whereas economic fundamental variables can only explain $21 \%$. We conclude that financialization partly transformed crude oil from a physical to a financial asset in terms of pricing behavior. This has important implications for the hedging effectiveness of commercial traders and the diversification benefits of commodity investors.

The remainder of the paper is organized as follows. Section 2 describes the methodology for measuring variable importance by decomposing the regression R-squared. We argue that our simple approach can address many of the shortcomings impairing the empirical findings. In section 3 we discuss the economic and financial key variables for our paper. While the economic variables are well known we thoroughly discuss the new financial variables that have emerged as important indicators of financialization over the last years. Section 4 shows the empirical results and discusses the implications for crude oil as a commodity. Section 5 concludes. 


\section{A Decomposition of Commodity Prices}

Monthly changes in commodity prices can be explained by economic fundamental variables on the one hand, and a set of financialization indicators on the other. While financialization is a recent phenomenon that is not yet fully understood, we show that its impact on commodity price movements is very real. In this chapter, we decompose the total variation of commodity prices into these two main categories. This decomposition can provide useful information about the relative importance and will be the main source of evidence for the emerging dominance of financialization in explaining commodity price movements. The measurement and quantification of variable importance is a long-standing question in statistics. A recent overview article is provided by Grömping (2015). Perhaps the most intuitive approach is to observe the increase in R-squared when a variable is added to a linear regression model. Unfortunately, the R-squared value of a regression is conditional on all other variables so that adding or removing a regressor alters the result. ${ }^{3}$

In this paper, we adopt a method originally proposed by Lindeman, Merenda, and Gold (1980) and further developed by Kruskal (1987). This approach has been termed the LMG method, named after its authors. Grömping (2015) shows that the LMG approach is superior to a number of other methods proposed in this field which either do not decompose the overall Rsquared, estimate negative R-squared contributions, or fail to be scale invariant. Most importantly, LMG is not order dependent since the average over all possible regressor orderings is taken. ${ }^{4}$ At the center of this approach lies the variance of $Y$ conditional on some regressors $X_{j}, j \in S$. The dependent variable $Y$ measures the prices, returns or volatilities of a commodity and the set of control variables $S$ contains the regressors excluding the variable whose importance we want to determine. When the variable of interest $X_{m}$ is added to the model the set of explanatory variables encompasses $M \cup S$ and the conditional variance of $Y$ is reduced. The sequentially added variance svar measures the contribution of the variable $X_{m}$ to the overall explanatory power of the model:

$$
\operatorname{svar}(M \mid S)=\operatorname{var}\left(Y \mid X_{j}, j \in S\right)-\operatorname{var}\left(Y \mid X_{m}, m \in M \cup S\right)
$$

${ }^{3}$ The situation simplifies considerably when the regressors are uncorrelated in which case the R-squared is independent from the presence of other variables. However, this special case is of little practical relevance.

${ }^{4}$ A theoretical justification is provided by Huettner and Sunder (2012) who show that the LMG method has a counterpart in cooperative game theory where the "worth" (R-squared) is efficiently distributed to the "players" (regressors) in a way that certain desirable properties are satisfied 
Since adding a variable will reduce the conditional variance of $Y$, svar will be nonnegative. ${ }^{5}$ As an example, consider a linear regression model with three regressors:

$$
y=\alpha+\beta_{1} x_{1}+\beta_{2} x_{2}+\beta_{3} x_{3}+\varepsilon .
$$

We are interested in the contribution of $x_{1}$ to the explanatory power of the model. There are $p !=3 !=6$ permutations for which we can arrange the regressors in Eq.(2) and, hence, six different ways to measure the contribution of $x_{1}$. To illustrate this case the six permutations are listed in Table 1. The second column shows the variance of $Y$ conditional on the regressors in $S$ and therefore excluding the variable of interest, $x_{1}$.

\section{$<<$ Table 1 about here $>>$}

The third column shows the conditional variance of $Y$ when $x_{1}$ is added to the model. The variables which do not enter the regression are indicated in grey. The sequentially added variance in Eq.(1) is then the difference between the second and the third column. The contribution of the variable $x_{1}$ to the explanatory power of the model is denoted as $\operatorname{LMG}\left(x_{1}\right)$ and is the fraction of the total variance of $Y$ explained by the average over all permutations:

$$
\operatorname{LMG}\left(x_{1}\right)=\frac{\frac{1}{p !} \sum_{i=1}^{p !} \operatorname{svar}\left(x_{1} \mid S(\pi)\right)}{\operatorname{Var}(Y)}
$$

The set of regressors $S$ changes over permutation $\pi$ as illustrated in Table 1 . Note that the first and the second permutations in Table 1 yield identical results. The same holds true for permutations five and six since the reordering of included variables does not change the conditional variance. Accordingly, there are only 4 unique values for svar in Table 1. Although this decision has little impact on the result, we follow the literature and sum over all six permutations. ${ }^{6}$ In our example, there are three LMG values $\left\{\operatorname{LMG}\left(x_{1}\right), \operatorname{LMG}\left(x_{2}\right), \operatorname{LMG}\left(x_{3}\right)\right\}$

${ }^{5}$ Note that the conditional variance of $Y$ can be described as $\operatorname{var}(Y \mid X)=E\left(Y^{2} \mid X\right)-[E(Y \mid X)]^{2}($ Casella and Berger 2002). The first term on the right hand side of this expression is the fitted values from a regression of $Y^{2}$ on the set of regressors in $X$. The second term is the squared fitted values from a regression of $Y$ on the same regressors. The conditional variance is therefore easy to estimate in an OLS framework.

${ }^{6}$ Our results are very close to those obtained with the R package relaimpo (Grömping, 2006) which also sums over all $p$ ! permutations. 
which together sum up to the overall R-squared of the regression model in Eq.(2). For the analysis in this paper we use the LMG approach to decompose the variation in commodity prices into economic fundamentals and financialization variables. This decomposition provides important evidence for the recent rise in financialization driven price movements.

\section{Data}

In this section, we present eight key variables that are used as inputs in our model to explain the variation in the time series of crude oil returns. Four variables represent the universe of fundamental economic variables. These are economic activity, real interest rates, the change in oil inventory levels, and the change in the trade-weighted value of the U.S. dollar. The importance of these variables for commodity markets and their economic mechanism have been thoroughly established in the literature. We will therefore review these variables only briefly. The other four variables are more recent but have been shown to be reliable measures of the financialization phenomenon. They include the CBOE volatility index (VIX), the returns in the S\&P 500, a measure of macroeconomic uncertainty, and the commodity futures risk premium. Their relevance and functioning in commodity markets are less well-known and we will discuss these variables more thoroughly.

Our first variable, Economic Activity, is a key variable for the demand of crude oil. Previous studies find a strong link between income and the demand for oil (Hamilton, 1983, 2009a, 2009b). Our empirical results are in line with these findings. In our model, economic activity can explain a large proportion of the variation in oil returns. In this paper, we use an index of global economic activity proposed by Kilian (2009). This index is particularly suited for our analysis because it measures the component of global real economic activity that drives the demand for industrial commodities. The index is constructed from dry cargo single voyage ocean freight rates and represents global demand for industrial commodities. The index is obtained by (1) taking the average over the growth rates of different freight rates, (2) deflating this average to accommodate the fact that the cost of shipping dry cargo has fallen in real terms over time, and (3) linearly detrending the real freight index in order to capture the cyclical 
variations. ${ }^{7}$ In recent empirical studies, the Kilian measure is an economically strong and statistically significant predictor of the demand for crude oil (see for instance Frankel, 2014)

Our second economic variable is the real interest rate. Real interest rates have been found to exhibit an inverse relationship with oil prices over time. Major oil price spikes that occurred in the early and late 1970s and during 2008 coincided with low real interest rates (Barsky and Kilian, 2004; Frankel, 2014). On the other hand, the period of low oil prices after 1982 was characterized by high real interest rates. Frankel (2014) describes three mechanisms through which higher interest rates cause a decline in oil prices. First, interest rates affect oil producing firms in their decision about how much oil to pump and how much oil to leave below ground for later extraction. Higher interest rates increase the incentive to extract more today and invest the proceeds at the higher interest rate. The oil supply will therefore increase pushing down oil prices. Second, a higher interest rate increases the financing costs of holding physical storage. Refineries and consumers of oil products therefore consume out of inventories rather than buying new supplies on the spot market. The demand for oil and hence oil prices decline. The third and last mechanism is capital switching. An increase in interest rates makes the investment in bonds more attractive. Financial investors will therefore redirect some of their commodity investments into bonds. The lower demand for commodity investments leads to a fall in prices. Together with our variable for economic activity, real interest rates are the main economic variable to explain the variation in oil market volatility. We define the real interest rate as the difference between the 3-month U.S. Treasury bill rate and the percentage year-on-year change in the consumer price index.

The third economic variable is the percentage change in oil inventory levels. Oil inventories respond to expectations concerning the future availability of crude oil (Pirong, 2008; Alquist and Kilian, 2010). Commodity consumers respond to fears of possible supply disruptions and stock-outs by increasing their physical inventory levels thereby increasing the price (Dvir and Rogoff, 2010). However, empirical studies on the effects of oil inventories are mixed. For instance, Kilian and Murphy (2014) investigate the role of inventories in the variation of oil prices and find that the relationship is rather unstable. Our empirical results are in line with this finding. The percentage change in inventory levels explains only a small part

${ }^{7}$ For a more detailed description of the individual steps involved in the construction of that index see Kilian (2009). An updated version of the index can be obtained from the home page of Lutz Kilian at http://wwwpersonal.umich.edu/ lkilian/reaupdate.txt 
of the variation in oil returns and volatility. Still, measures of oil inventories are frequently used in empirical work and we decided to include the inventory variable for completeness.

The fourth and last fundamental economic variable in our model is the percentage change in the U.S. dollar exchange rate. Crude oil is traded in world markets and is denominated in U.S. dollars. An appreciation of the dollar means higher costs for oil importing countries. If the dollar appreciates, importing countries will ask for lower oil prices in order to be compensated for an exchange rate loss. At the same time, oil exporting countries receive additional exchange rate profits when paid in dollars and have some scope for reducing oil prices. Oil prices and the dollar exchange rate are therefore inversely related. Fratzscher et al. (2014) estimate the elasticity to be -0.7. A number of empirical studies confirm the importance of the U.S. dollar exchange rate for explaining crude oil prices, both in the short run (Amano and van Norden, 1998; Lantz and Simon, 2000; Sadorsky, 2000), and in the long run (Zhang, et al., 2008). Our measure for the dollar exchange rate is the U.S. trade weighted value of the U.S. dollar against major currencies.

Figure 1 shows the monthly observations for our economic variables from January 1990 to December 2015. The Kilian index shows high levels of economic activity in the first half of the 2000s, which corresponds to a price boom for many commodities. In the years following the Lehman Brothers default economic activity decreases reflecting the impact of the great recession. Real Interest rates are declining throughout our sample and are negative for later years. Although some studies argue that the financialization of commodity markets started in 2004, more recent empirical papers find that the Lehman Brothers bankruptcy marks the beginning of a fundamental change in the behavior of commodities (Adams and Glück, 2015). We therefore label the period up to August 2008 as the "pre-financialization period" and the period starting in September 2008 at the "financialization period".

$$
<<\text { Figure } 1 \text { about here }>>
$$

The first of the four considered financialization variables is the VIX volatility index. The VIX measures the implied volatility of S\&P 500 index options and has proved a strong proxy for investors' attitude toward risk (IMF, 2004; Hartelius et al, 2008; Sari et al., 2011). The VIX is also used as a proxy for the risk absorption capacity of financial traders in commodity markets. Cheng, Kirilenko, and Xiong (2015) show that high levels of the VIX index reverse the flows from financial investors into commodity markets, thereby depressing prices. Silvennoinen and Thorp (2013) show that the integration between commodities and financial 
market is higher with increasing VIX levels. In our paper, we find that the VIX has become an important variable in explaining the volatility in crude oil returns.

The second financialization variable is the return in the $S \& P 500$ index. The $S \& \mathrm{P} 500$ is a key variable in our analysis. Financialization describes the phenomenon that something becomes more "finance like" and hence can be explained by financial assets like stock price movements. The degree to which oil prices can be explained by stock market returns therefore gives a direct indication of the intensity of the financialization process. Although studies that were already published in the pre-financialization period find a link between stock markets and crude oil, the magnitude of this link has increased dramatically since the beginning of the financialization period (Aloui and Jammazi, 2009; Bharn and Nikolovann, 2010; Lee and Chiou, 2011).

The variable Macroeconomic Uncertainty causes informational frictions in commodity markets and can confuse market participants into a behavior that amplifies the speculative effects of financialization (Cheng and Xiong, 2014). In an ideal world without informational frictions, speculative demand from financial investors is compensated by lower demand from commodity consumers (cost effect). Knowing that the current price level reflects speculative rather than fundamental factors, commodity consumers reduce their futures long positions and consume out of inventories. As a consequence of the lower demand from consumers, commodity prices decrease and the speculative demand of financial investors cannot generate momentum.

In the real world, however, current demand and supply, and therefore the fair futures price, is unobservable by market participants. The current size of below ground inventories, above ground inventories, and ship-board supplies is unknown. Demand indicators such as industrial production are published with a lag and are frequently revised. In the presence of informational frictions, it will be therefore difficult for traders to distinguish commodity price movements caused by speculation from those caused by changes in economic activity. In this environment, daily futures prices assume an important signaling function and are frequently considered as the best real time indicator of economic activity available (Sockin and Xiong, 2015). An increase in commodity prices driven by speculation will be at least partly attributed to higher economic activity. Expecting a higher demand for their finished products in the futures, commodity consumers respond to the increase by increasing their demand for that commodity despite higher prices. In other words, the cost effect that deters additional demand in the absence of informational frictions is now compensated by a signaling effect encouraging 
additional demand. As a consequence, commercial hedgers contribute to the speculative price increase rather than compensating for it. Once the price increase develops momentum, an endogenous price spiral emerges that attracts even more speculation in the market confirming the initial views of the market participants. The price momentum will continue until reliable data on actual economic demand becomes available to traders, correcting their views on price increase. The additional demand will reverse and price will start to fall. The extreme oil price rise in the first half of 2008 when the WTI price increased by over $50 \%$ followed by an equally severe fall in prices in 2009 needs to be interpreted in this light Cheng and Xiong (2014).

The speculative impact that financial traders have on commodity prices is therefore directly related to the amount of uncertainty in the economy. In this paper, we test for the impact of macroeconomic uncertainty on crude oil prices using a recent measure proposed by Jurado, Ludvigson, and Ng (2015), henceforth denoted as "JLN". This measure is based on the idea that what matters for an indicator of economic uncertainty is whether the economy has become more or less predictable and, therefore, more or less uncertain. This view differs from traditional measures which tend to be based on the idea whether particular economic indicators have become more or less variable. ${ }^{8}$ The JLN uncertainty measure is estimated as the conditional volatility of the prediction error of an economic indicator, thus measuring the variability in the unforecastable components of a series.

$$
\mathcal{U}_{j t}(h) \equiv \sqrt{E\left[\left(y_{t+h}-E\left[y_{t+h} \mid I_{t}\right]\right)^{2} \mid I_{t}\right]}
$$

where $\mathcal{U}_{j t}(h)$ is the uncertainty of variable $j$ at time $t$ with forecast horizon $h$. The macroeconomic uncertainty is then computed by taking the average over more than 130 economic indicators such as industrial production, employment, and hours worked.

$$
\mathcal{U}_{t}(h) \equiv \sum_{j=1}^{N} w_{j} \mathcal{U}_{j t}(h)
$$

\footnotetext{
${ }^{8}$ In the past, a number of alternative uncertainty measures have been proposed, the most common one being some function of stock market volatility, either estimated from stock prices directly or by the VIX volatility index. However, a measure of financial market volatility is likely to be driven by factors associated with time-varying risk-aversion rather than economic uncertainty (Bekaert, Hoerova, and Duca, 2013). Another popular approach is based on measures of disagreement among professional forecasters (D'Amico and Orphanides, 2008). However, disagreements in survey forecasts could be due to differences in opinion rather than uncertainty (Mankiw, Reis, and Wolfers, 2004).
} 
Jurado, Ludvigson, and $\mathrm{Ng}$ (2015) show that the time-variation in the uncertainty measure in Eq.(5) is quite different from other common alternatives like the VIX index. For instance, significant uncertainty episodes occur less frequently than in other popular measures but when the do occur, they are larger, more persistent, and have a larger negative impact on real activity. ${ }^{9}$

The fourth and last variable that has been used in the literature to model financialization is the Risk Premium. We have decided to use the risk premium instead of another variable that has been the focus of many recent empirical papers: the net long futures positions of financial investors. At first glance, the importance of net long positions seems straightforward: rising interest in commodity markets from financial investors leads to higher demand for commodity futures long positions. The demand for futures long positions usually comes in one of two forms: in the case of retail investors, money flows into commodity ETFs which replicate an index such as the S\&P GSCI by investing in the underlying futures contracts (Irwin, 2013). In contrast, institutional investors usually engage a commodity swap dealer who in turn hedges via the futures market (Cheng and Xiong, 2014). Thus, the majority of demand coming from financial investors increases the demand for futures long positions. Although the relevance of this variable seems to be clear, a large body of empirical studies does not find a statistically significant effect of net futures long positions as a predictor of commodity prices (see for instance Alquist and Gervais, 2013; Brunetti et al, 2011; Sanders and Irwin, 2011). One problem is that commodity futures positions held by financial investors are difficult to measure. Although the CFTC publishes futures positions of speculators in the index investment data report a number of studies have raised concerns about the quality of that data (e.g. Irwin and Sanders, 2012; Cheng and Xiong, 2014). On the one hand, the role of some companies classified as "commodity swap dealers" seems to be unclear as they service both, financial investors and commercial hedgers. On the other hand, commercial hedgers themselves can engage in financial activity that is typically associated with financial investors. Other attempts of inferring investor positions from data include the imputed methods of Masters (2008) and Singleton (2014). In practice, these imputed holdings have shown some unexpected behavior. For instance, a direct measure of crude oil index holdings does a poorer job at predicting oil prices than the index imputed from agricultural holdings used in Singletons paper (Hamilton and Wu, 2015; Irwin

\footnotetext{
${ }^{9}$ In addition to the macroeconomic uncertainty variable Jurado, Ludvigson, and $\mathrm{Ng}$ (2015) also provide a
} measure of financial uncertainty which has a very similar interpretation to the VIX. If we swap the VIX index with this measure of financial uncertainty we obtain qualitatively similar results. Results are not shown but are available from the authors upon request. 
and Sanders, 2012). Our reading of the literature is that the quality of currently available data on financial investor positions needs to improve in order to contain information that is useful to explain the variation in commodity prices.

In this paper, we will therefore use the commodity futures risk premium which is the difference between the spot price that is expected at a future point $T$ and the current futures price with maturity $T$ :

$$
R P_{t}=E_{t}\left[S_{T}\right]-F_{t, T}
$$

The risk premium reflects the demand imbalance for commodity futures positions. Commodity producers demand short positions in order to lock in a price at which they can sell their products over the next months. During normal times, they outnumber the demand for futures long positions coming from speculators or arbitrageurs in the market. In the terms of Cheng, Kirilenko, and Xiong (2015), commodity producers are initiating the trade and need to pay a risk premium to the market participants who are accommodating the trade. The risk premium is therefore usually positive. If the investment demand from financial investors increases, they can outnumber the commodity producers in which case speculators need to pay a risk premium and producers now become the recipients of that premium. The risk premium turns negative. Using the time-variation in the risk premium therefore allows us to learn about the speculative demand for commodity futures without the need to rely on a direct but noisy position measure. Baumeister and Kilian (2016) compare recent measures of the risk premium and conclude that the risk premium estimation proposed by Hamilton and $\mathrm{Wu}$ (2014) is the most accurate one. In this paper, we follow their recommendation and use an updated version of the Hamilton and $\mathrm{Wu}(2014)$ risk premium.

Figure 2 shows the monthly observations for our financialization variables from January 1990 to December 2015. The high levels of the volatility index VIX after the Lehman Brothers default in 2008 indicate a period of financial distress. During the same time, the returns of the S\&P 500 index were strongly negative. September 2008 therefore represents a structural break for our financial variables but also for the behavior of commodity prices. The remaining two variables, macroeconomic uncertainty and risk premium, also respond strongly to the events in 2008. Uncertainty about macroeconomic events reached a historical high and the risk premium turns negative. Although investors temporarily reversed their flows into commodities in 2008, the negative risk premium shows a general imbalance in the number of financial investor money relative to hedging demand. 
In Figure 3 we show sample correlations between all eight key variables driving commodity markets. With a few exceptions, the correlations are close to zero. For instance, the correlation between macroeconomic uncertainty and the VIX index shows a moderate level of 0.58 , which is in line with the argument in Jurado, Ludvigson, and $\mathrm{Ng}$ (2015) that the VIX is a measure of financial distress and not an indicator of general market uncertainty. The positive correlation between the risk premium and real interest rates can be explained by the capital switching argument: if the returns on bonds are low, investors channel their funds into other assets including commodities, leading to an excess demand for long positions thereby driving down the risk premium. The other correlations are as expected. For instance, if the returns of the S\&P 500 are negative the VIX index will be high. From Figure 3 we conclude that every variable contains sufficient own variation to justify inclusion into our model.

$<$ Figure 3 about here $>>$

\section{Empirical Results}

In this section we decompose the total variation of crude oil returns and volatility into three distinctive parts: One part that can be explained by economic fundamental factors, one part that can be explained by financialization variables, and a third which consists of the unexplained variation. While decomposing the returns provides information concerning the main drivers of crude oil as an asset, the volatility decomposition reveals the main factors of risk transmission. We show that the relative importance of economic and financial variables changes over time. In particular, the relative importance of financial variables has changed in such a way that crude oil is now closer to a financial asset than to a real physical asset.

Panel A of Figure 4 shows the decomposition of the total variation in crude oil returns. The fraction of the total variation that can be explained by movements in economic variables is indicated by green shaded areas, the percentage that can be explained by financial variables is indicated by the red shaded areas. The remaining variation is unexplained. The large share of unexplained variation may be due to omitted factors such as geopolitical changes, synchronized OPEC oil production, and disrupting weather events. At a given point in time, the sum over all green and red shaded areas represents the R-squared from a regression of monthly crude oil returns on our set of explanatory variables. To obtain time variation, the regression is moved 
forward in a 5-year rolling window (60 monthly observations). ${ }^{10}$ Two observations follow from Figure 4: During the pre-financialization period, the contemporaneous variation in our eight regressors explains only a small percentage of the total variation in crude oil returns. After the default of Lehman Brothers, the situation changes dramatically. The same set of regressors now explain almost $60 \%$ of the return variation. Among the fundamental variables, economic activity and the change in the dollar exchange rate explain $8 \%$ and $12 \%$ respectively. The main drivers behind the variation in oil returns are however the financial variables. In particular, the change in the VIX and the S\&P 500 returns are responsible for $29 \%$ of the variation.

\section{$<<$ Figure 4 about here $>>$}

To illustrate this point, the average fraction explained by each set of variables is shown in Panel B of Figure 4. Since the beginning of the financialization period, the financial variables dominate the economic fundamental variables by a significant amount. Traditional fundamental variables have become relatively less important for predicting crude oil returns while recent financial variables can now predict a large share of the return variation. From this finding we conclude that the behavior of crude oil has become more similar to that of financial assets like equities rather than traditional economic demand and supply drivers.

In Figure 5 we extend our analysis to the volatility of oil returns. Panel A shows that economic activity and the interest rate are the main economic variables driving crude oil volatility. Among the set of financial variables, stock market volatility (VIX), macroeconomic uncertainty, and the futures risk premium can explain the majority of oil volatility. Similar to our previous analysis, the financial variables become the dominant drivers behind the crude oil variation. Panel B of Figure 5 shows that today, 53\% of the total variation in oil volatility can be explained by financial variables while only $21 \%$ can be explained by fundamental economic variables. Our empirical findings suggest that financial variables are not only responsible for explaining crude oil behavior but also for the transmission of risk to crude oil markets.

\section{$<$ Figure 5 about here $>>$}

The size and persistence of our results suggest that the financialization of commodity markets may be more than a temporary phenomenon. If financial investors are the cause of the

10 The 5-year window is to some extent arbitrary but reflects the trade-off between using a large window in which important events are oversmoothed and using a smaller window in which the number of observations is small and the time-variation in the R-squared is erratic. 
financialization process the change in nature towards a financial asset is likely to continue until other assets attract investor attention causing a redirection of investment flows

\section{Conclusion}

In this paper, we investigate the impact of ten years of financialization on the commodity environment. The main question we try to answer is whether commodities have transformed from a physical to a financial asset. Our empirical design is based on four fundamental variables (economic activity, real interest rates, the change in oil inventory levels, and the change in the trade-weighted value of the U.S. dollar) and four indicators of financialization (VIX, the returns of the S\&P 500, a measure of macroeconomic uncertainty, and the commodity futures risk premium). To address our research question, we determine the importance of each variable in explaining the total variation in crude oil returns and volatility. Using a 5-year rolling window, we show that while fundamental variables remain important drivers of the crude oil market, the majority of the oil price movements today can be explained by financial variables. For instance, while financial variables can only explain $11 \%$ of the total variation in crude oil returns in the years prior to financialization, the impact grows to $35 \%$, becoming the main drivers behind oil price movements. We estimate an even stronger effect on crude oil volatility where the impact of financial variables grows from $19 \%$ in the pre-financialization period to $53 \%$ since the failure of Lehman Brothers. Our empirical results indicate that crude oil markets underwent significant changes over the last years. These changes were sufficiently large to transform the very nature of crude oil, away from a physical real asset towards a variable that shows a behavior that is comparable to stocks, bonds, and other financial assets. Although our results are silent on the exact economic mechanism behind these changes, our findings have important implications. With financialization, commodities are unlikely to provide effective diversification benefits in a mixed-asset portfolio, the prices of daily foodstuffs and energy costs are likely to fluctuate with changes in oil markets, and the forecast of future oil prices based on traditional economic indicators becomes imprecise (Master, 2008).

In this paper, we presented some promising preliminary results on the transformation of oil from a physical to a financial asset. In the following months, we aim to expand our work along two lines. First, we will test whether our findings for the crude oil market apply to the commodity market in general. A number of different commodities have been reported to respond to the financialization process. For instance, Tang and Xiong (2012) show that financialization had its largest impact on commodities that are part of popular indices such as the S\&P GSCI and the Bloomberg Commodity index. We will therefore extend our analysis to 
other energy products, in particular heating oil, to agricultural commodities such as corn and wheat, and to industrial and precious metals such as copper and gold. In this way, almost $75 \%$ of S\&P GSCI index will be covered. Our second extension will address the specific functional form of your regression model. So far, we have chosen a simple specification because we believe that simple forms have some advantages in terms of transparency and credibility. However, we are not dependent on a particular form. We do not interpret the regression coefficients in a causal way and in fact do not have any requirement in the coefficient estimates. We can therefore extend the R-squared decomposition to related goodness of fit measures in non-linear regressions. This would add flexibility do our analysis and answer the question to what extent our results depend on the assumption of linearity. 


\section{References}

Adams, Z. and T.Glück (2015), "Financialization in Commodity Markets: A Passing Trend or the New Normal?" Journal of Banking and Finance 60, 93-111.

Aloui, C, and R. Jammazi (2009), "The Effects of Crude Oil Shocks on Stock Market Shifts Behaviour: A Regime Switching Approach”, Energy Economics 31(5), 789-799.

Alquist, R., and O. Gervais (2013), "The Role of Financial Speculation in Driving the Price of Crude Oil”, The Energy Journal 34(3), 35-54.

Alquist, R., and L. Kilian (2010). "What Do We Learn from the Price of Crude Oil Futures?" Journal of Applied Econometrics 25, 539-573.

Amano R.A., and S. van Norden (1998), "Oil Prices and the Rise and Fall of the US Real Exchange Rate", Journal of International Money and Finance 17, 299-316.

Barsky, R.B., and L. Kilian (2004), "Oil and the Macroeconomy since the 1970s”, The Journal of Economic Perspectives 18(4), 115-134.

Bahrn R. and B. Nikolovann (2010), "Global oil prices, oil industry and equity returns: Russian experience", Scottish Journal of Political Economy, 57 (2) (2010), pp. 169-186

Bekaert, G., M. Hoerova, and M.L. Duca (2013), "Risk, Uncertainty and Monetary Policy”, Journal of Monetary Economics 60(7), 771-788.

Brunetti, C., B. Büyükşahin, and J.H. Harris (2011), "Speculators, Prices and Market Volatility", working paper available at https://ssrn.com/abstract=1736737.

Büyükşahin, B. and J. Harris (2011), “Do Speculators Drive Crude Oil Prices?”, Energy Journal, 32(2), 167-202.

Cheng, I.-H. and W. Xiong (2014), "Financialization of Commodity Markets", Annual Review of Financial Economics 6, 419-441.

Cheng, I.-H., A. Kirilenko, and W. Xiong (2015), „Convective Risk Flows in Commodity Futures Markets“, Review of Finance 19, 1733-1781.

D'Amico, S., and A. Orphanides (2008), "Uncertainty and Disagreement in Economic Forecasting", Federal Reserve Board Finance and Economics Discussion Series 2008-56.

Filis, G., S. Degiannakis, and C. Floros (2011), "Dynamic Correlation Between Stock Market and Oil Prices: The Case of Oil-Importing and Oil-Exporting countries" International Review of Financial Analysis 20(3), 152-164.

Frankel, J. A. (2014), "Effects of Speculation and Interest Rates in a "Carry Trade" Model of Commodity Prices”, Journal of International Money and Finance 42, 88-112.

Fratzscher, M., D. Schneider, and I. Van Robays (2014), "Oil Prices, Exchange Rates and Asset Prices" European Central Bank Working Paper Series 1689, available at https://www.ecb.europa.eu /pub/pdf/scpwps/ecbwp1689.pdf

Grömping, U. (2006), "Relative Importance for Linear Regression in R: The Package relaimpo”, Journal of Statistical Software 17(1), 1-27.

Grömping, U. (2015), "Variable Importance in Regression Models", WIREs Computational Statistics 7 , $137-152$.

Hamilton J.D. (1983), "Oil and the Macroeconomy since World War II", The Journal of Political Economy 91(2), 228-248. 
Hamilton D.J. (2009a), “Understanding Crude Oil Prices”, Energy Journal 30(2), 179-206.

Hamilton D.J. (2009b), "Causes and Consequences of the Oil Shock of 2007-08”, Brookings Papers on Economic Activity, 215-261.

Hamilton, J.D., and J.C. Wu (2014), "Risk Premia in Crude Oil Futures Prices", Journal of International Money and Finance 42, 9-37.

Hamilton, J.D., and J.C. Wu (2015), "Effects of Index-Fund Investing on Commodity Futures Prices", International Economic Review 56(1), 187-205.

Hartelius, K., K. Kashiwase, and L.E. Kodres (2008), "Emerging Market Spread Compression: Is it Real or Is it Liquidity?", International Monetary Fund working paper No. 08/10, available at https://www.imf.org/external/pubs/ft/wp/2008/wp0810.pdf

Henderson, B., N. Pearson, and L. Wang (2015), "New Evidence on the Financialization of Commodity Markets", Review of Financial Studies 28(5), 1285-1311.

Huettner, F., and M. Sunder (2012), “Axiomatic Arguments for Decomposing Goodness of Fit according to Shapley and Owen Values", Electronic Journal of Statistics 6, 1239-1250.

IMF (2004), "Global Financial Stability Report, Market Developments and Issues", International Monetary Fund, available at https://www.imf.org/external/pubs/ft/gfsr/.

Irwin, S.H. (2013), "Commodity Index Investment and Food Prices: Does the "Masters Hypothesis" Explain Recent Price Spikes?”, Agricultural Economics 44, 29-41.

Irwin, S.H. and D.R. Sanders (2011), "Index Funds, Financialization, and Commodity Futures Markets", Applied Economic Perspectives and Policy, 33(1), 1-31.

Irwin, S.H. and D.R. Sanders (2012), "Testing the Masters Hypothesis in Commodity Futures Markets", Energy Economics, 34, 256-269.

Jurado, K., S.C. Ludvigson, and S. Ng (2015), “Measuring Uncertainty”, American Economic Review 105(3), 1177-1216.

Kilian, L. (2009), "Not All Oil Price Shocks are Alike: Disentangling Demand and Supply Shocks in the Crude Oil Market", American Economic Review 99(3), 1053-1069.

Kilian, L., and D.P. Murphy (2014), "The Role of Inventories and Speculative Trading in the Global Market for Crude Oil”, Journal of Applied Econometrics 29(3), 454-478.

Kilian, L., A. Rebucci, and N. Spatafora (2009), “Oil Shocks and External Balances”, Journal of International Economics 77,181-194.

Kruskal, W. (1987), "Relative Importance by Averaging over Orderings", The American Statisticican $41,6-10$.

Lee Y.-H. and S.Chiou (2011), "Oil Sensitivity and Its Asymmetric Impact on the Stock Market", Energy, 36, 168-174.

Lindeman, R.H., P.F. Merenda, and R.Z. Gold (1980), "Introduction to Bivariate and Multivariate Analysis" Glenview, IL: Scott, Foresman.

Mankiw, N.G., R. Reis, and J. Wolfers (2004), “Disagreement about Inflation Expectations”, In NBER Macroeconomics Annual 2003, edited by Mark Gertler and Kenneth Rogoff , 209-248, Cambridge, MA, MIT Press.

Masters, M.W. (2008), "Testimony before the Committee on Homeland Security and Governmental Affairs of the United States Senate", May 20, 2008. 
Sadorsky P. (2000), “Oil Price Shocks and Stock Market Activity”, Energy Economics 21, 449-469.

Sanders, D.R., and S.H. Irwin (2011), "The Impact of Index Funds in Commodity Futures Markets: A Systems Approach", Journal of Alternative Investments 14, 40-49.

Sari, R., U. Soytas, and E. Hacihasanoglu (2011), "Do Global Risk Perceptions Influence World Oil Prices?" Energy Economics 33(3), 515-524.

Silvennoinen, A., and S. Thorp (2013), "Financialization, Crisis and Commodity Correlation Dynamics, Journal of International Financial Markets, Institutions and Money 24, 42-65.

Singleton, K.J. (2014), "Investor Flows and the 2008 Boom/Bust in Oil Prices", Management Science $60,300-318$.

Sockin, M., and W. Xiong (2015), "Informational Frictions and Commodity Markets", The Journal of Finance 70(5), 2063-2098.

Tang, K. and W. Xiong (2012), "Index Investment and the Financialization of Commodities", Financial Analysts Journal, 68(6), 54-74.

Zhang, Y.-J., Y. Fan, H.-T. Tsai, and Y.-M. Wei (2008), "Spillover Effect of US Dollar Exchange Rate on Oil Prices", Journal of Policy Modelling 30(6), 973-991. 


\section{Appendix A: Unit Root Tests and Real Crude Oil Prices}

In this appendix, we discuss the possibility to extend our analysis to the (real) prices of crude oil. Most studies investigate returns or the volatility of commodity returns to avoid problems arising from non-stationarity in prices. However, if carefully implemented, one can apply the analysis in our paper also to oil price levels. In the following, we will briefly explain the methodological approach and discuss why the empirical evidence for prices is weaker.

Conventional unit root tests fail to reject the null hypothesis in the presence of structural breaks. Perron (1989) showed that many macroeconomic time series can be found to be (trend) stationary once exogenous shocks such as financial crises are accounted for. In the Perron (1989) approach, structural breaks are interpreted as exogenous shocks that are identified by visual inspection of the data. Zivot and Andrews (1992) extend this idea by proposing a procedure that tests for the occurrence of breaks at unknown points in time. These breaks could occur in form of a level shift, $D U$ or a change in the slope of the time series, $D T$. The oil price series used in this paper appears to suffer from both types of structural breaks: after a period of slightly declining growth during the 1990s, oil prices moved on a distinct upward trajectory starting in 1998. The growth path includes the pronounced 2008-2009 oil price boom and bust and loses its momentum in the first half of 2014 where it fluctuates around a price of $\$ 110$ per barrel. The year 1998 therefore marks a change in the trend of oil prices. The June 2014 oil price drop marks a second change which appears to have affected both, the trend and the level of oil prices: Within a few months, oil prices dropped to $\$ 50$ and below. The Zivot-Andrews test identifies a structural break in the level and trend of oil prices in September 2014 which is close to the widely noted oil price drop that started in June 2014. The Zivot-Andrews test is limited to detect one structural break. In order to detect the second break in 2014 we apply the test to two subsamples of our data. Sample 1 ranges from January 1990 to June 2014. Sample 2 ranges from January 2011 to June 2016. We decided to use overlapping samples to allow for a sufficiently large observation sample. The date and type of structural breaks identified by the Zivot-Andrews test are illustrated in Panel A of Figure A1. The test is applied to the level of real Brent oil prices. Panel B shows the test statistics of the conventional Augmented Dickey Fuller and the Phillips-Perron tests. The conventional unit root tests cannot account for the presence of breaks and hence fail to reject the null hypothesis of a unit root. ${ }^{11}$ In contrast, the Zivot Andrews test indicates stationarity and rejects the null hypothesis on the $1 \%$ significance

\footnotetext{
${ }^{11}$ For the first sample, the Phillips-Perron test finds weak evidence for stationarity at the $10 \%$ level.
} 
level. Once we account for the presence of structural breaks, we can therefore examine the financialization in real crude oil prices rather than their percentage changes.

Figure A1: Unit Root Tests for Crude Oil Price Levels

\section{Panel A: Structural Breaks in the Levels of Real Crude Oil Prices}

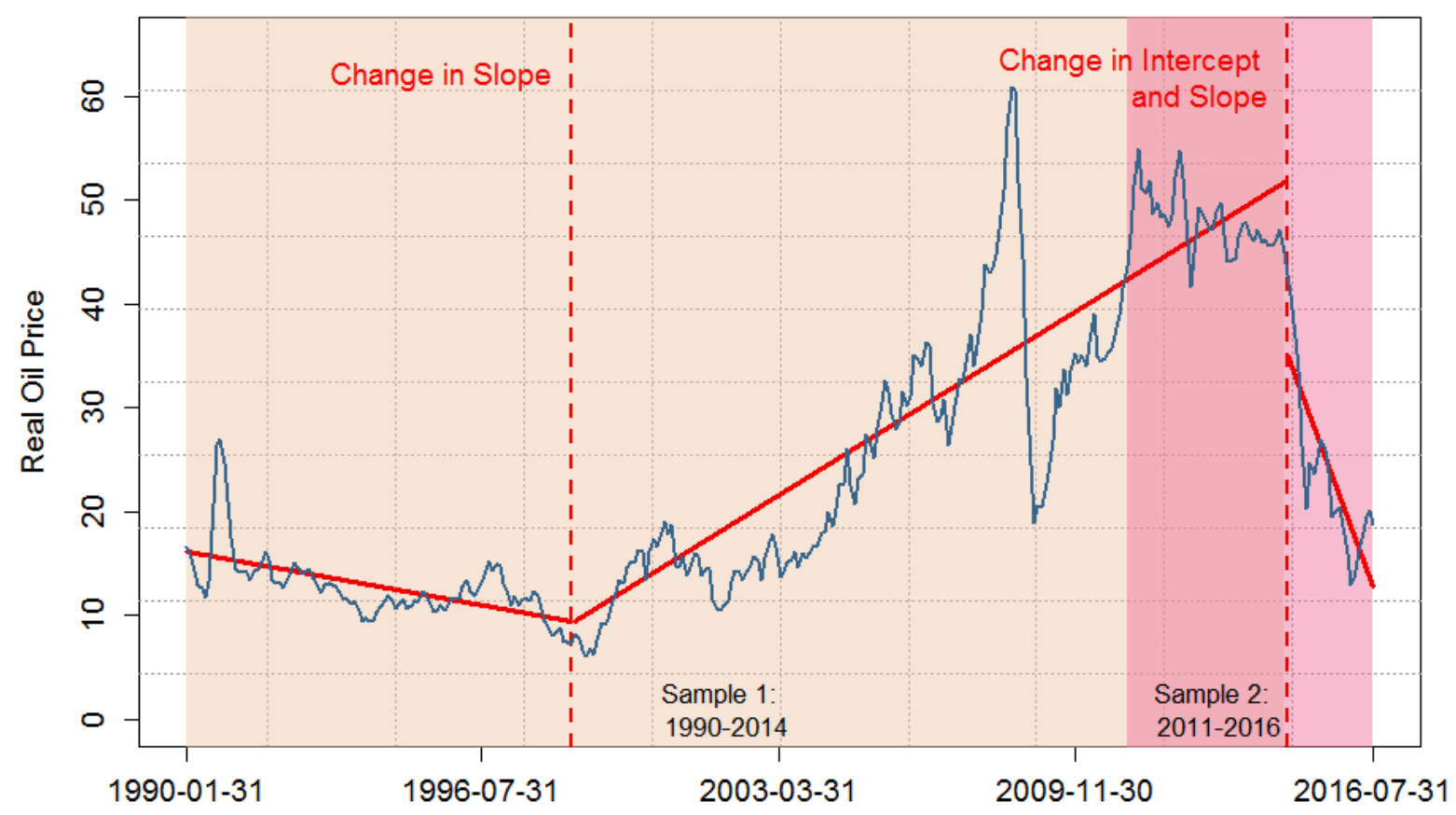

Panel B: Standard Unit Root and Zivot-Andrews (1992) Test Statistics

Sample $1(1990$ - 2014)

ADF

PP

ZA
$-2.34$

$-19.37^{*}$

$-5.18^{* * * *}$
Sample 2 (2011 - 2016)

ADF

PP

ZA

$-5.94^{* * * *}$

This figure shows the results from applying the Zivot-Andrews (1992) unit root test to the level of real crude oil prices. Panel A shows that the time series of oil prices seems to be affected by two structural breaks. The first change is related to the slope of the price trend which the test detects to occur in August 1998. The second change affects both, the level and the trend of crude oil prices and is detected in September 2014. The regression equation used for the first sample is $P_{t}=\hat{\mu}+\hat{\beta} t+\hat{\gamma} D T+\hat{\alpha} P_{t-1}+\sum_{j=1}^{k} \hat{c}_{j} \Delta P_{t-j}+e_{t}$ where $P_{t}$ denotes real oil prices, and $D T$ indicates the additional increase in the price trend. The regression equation used in the second sample incorporates both types of shifts and is expressed as $P_{t}=\hat{\mu}+\hat{\theta} D U_{t}+\hat{\beta} t+\hat{\gamma} D T+\hat{\alpha} P_{t-1}+\sum_{j=1}^{k} \hat{c}_{j} \Delta P_{t-j}+e_{t}$. The lag length $k$ is determined using the same selection procedure as in Perron (1989) and Zivot and Andrews (1992). In our case, only the first lag was significant so that the test statistics shown in Panel B are based on $k=1$. 
Panel A of Figure A2 shows the decomposition of the total variation in real crude oil prices. The fraction of the total variation that can be attributed by structural breaks is indicated by yellow shaded areas. The share of the total variation that can be explained by movements in economic variables is indicated by green shaded areas. The percentage that can be explained by financial variables is indicated by the red shaded areas. The remaining variation is unexplained.

Figure A2: Decomposition of Real Crude Oil Prices

\section{Panel A: Relative Importance of Fundamental and Financial Factors}

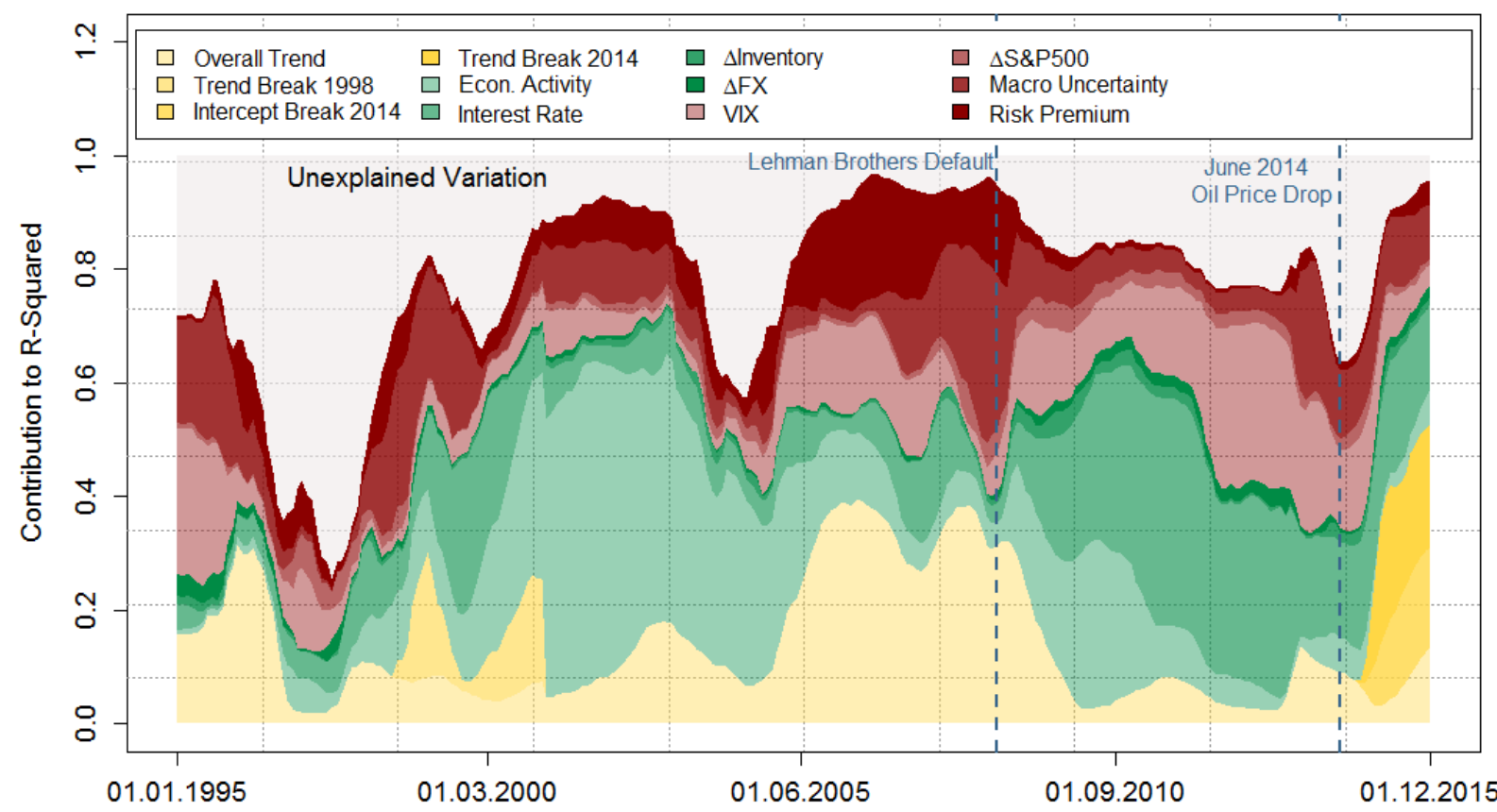

Panel B: Relative Importance Shares in Subsamples

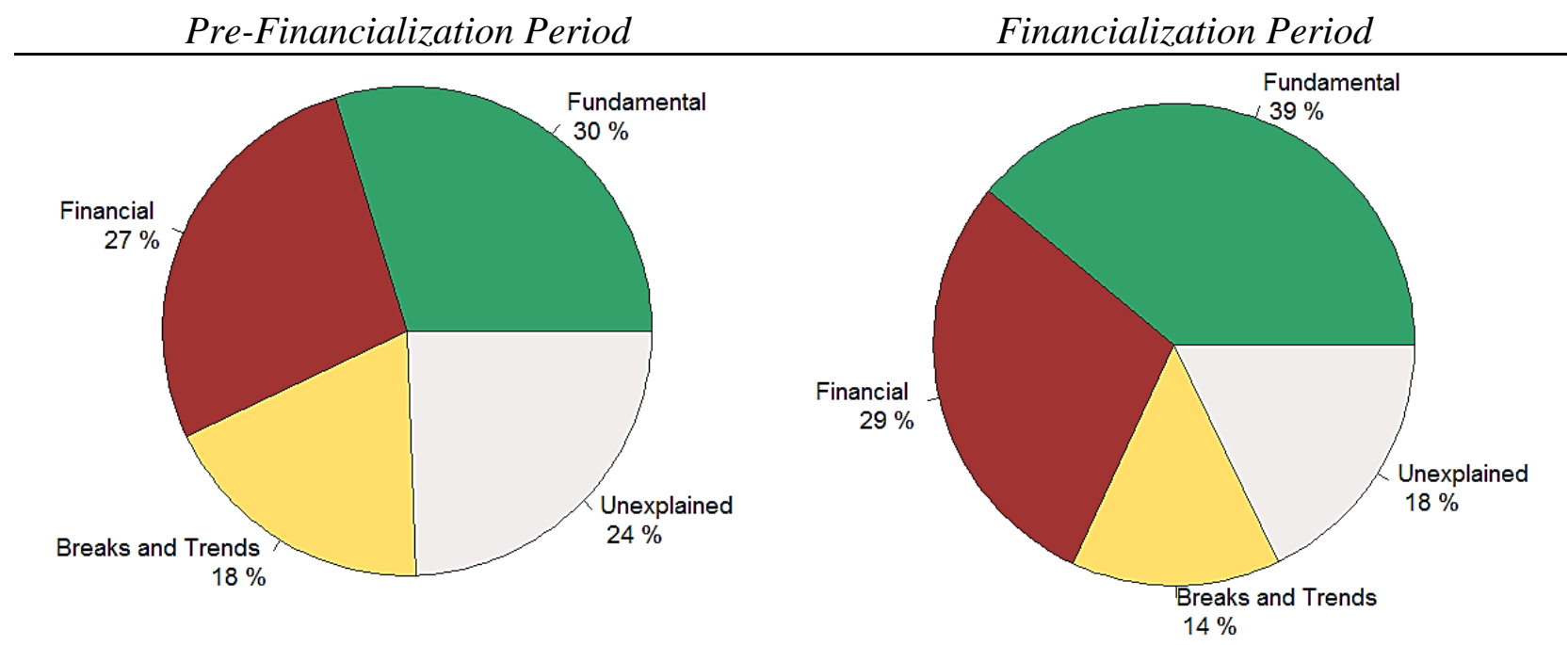

This figure shows the relative importance of economic fundamental and financial variables in explaining the total variation of real crude oil prices. Green shaded areas denote the contribution of economic variables to the regression Rsquared. Red shaded areas denote the contribution of financial variables. Yellow areas denote the contribution of structural breaks in the level and trend of real oil prices. For a given month, the sum over all shaded areas denotes the overall R-squared of the regression. The remaining area represents the unexplained variation in real crude oil prices. 
Overall, our set of regressors can explain a large share of the variation in real oil prices. Compared to our findings concerning returns and volatility, prices seem to be easier to predict. This could also explain why some papers prefer an analysis of oil price levels rather than percentage changes (e.g. Frankel, 2014). One drawback of analyzing price levels is that the economic determinants behind the structural breaks remain obscure. It is unclear whether they can be attributed to economic or financial factors. Compared to the analysis of returns or volatility, the inspection of price level data therefore has some disadvantages. Panel B of Figure A2 shows the average fraction explained by each set of variables. In contrast to our findings on returns and volatility, the role of financial variables is less clear. We conclude that there is strong evidence for the increasing dominance of financial variables for explaining the variation in crude oil returns and volatility but that the analysis based on price level data is inconclusive. 
Figure 1: Variables Measuring the Economic Fundamentals of Commodity Markets

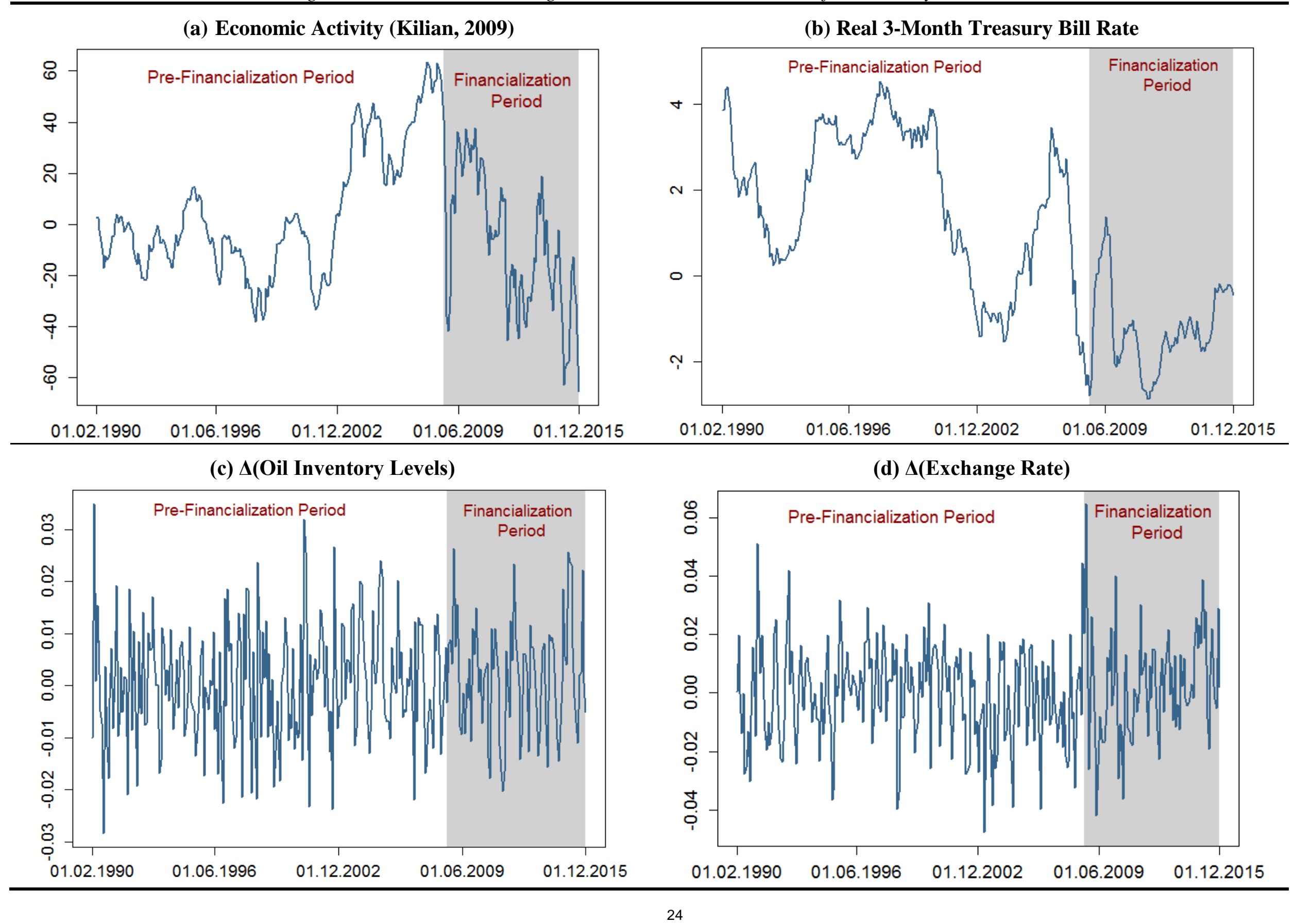


Figure 2: Variables Measuring the Financialization of Commodity Markets

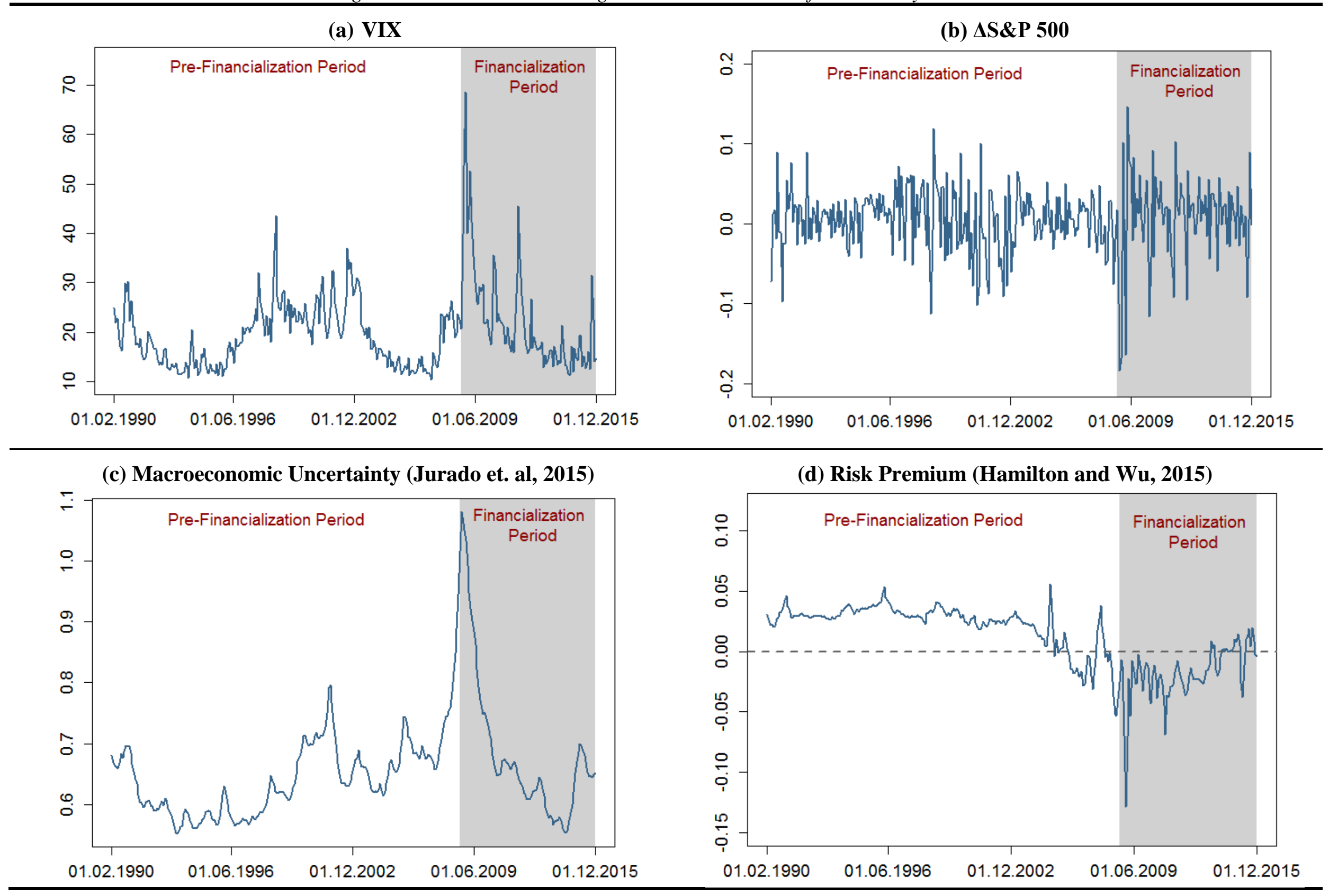


Figure 3: Sample Correlations (1990-2015)

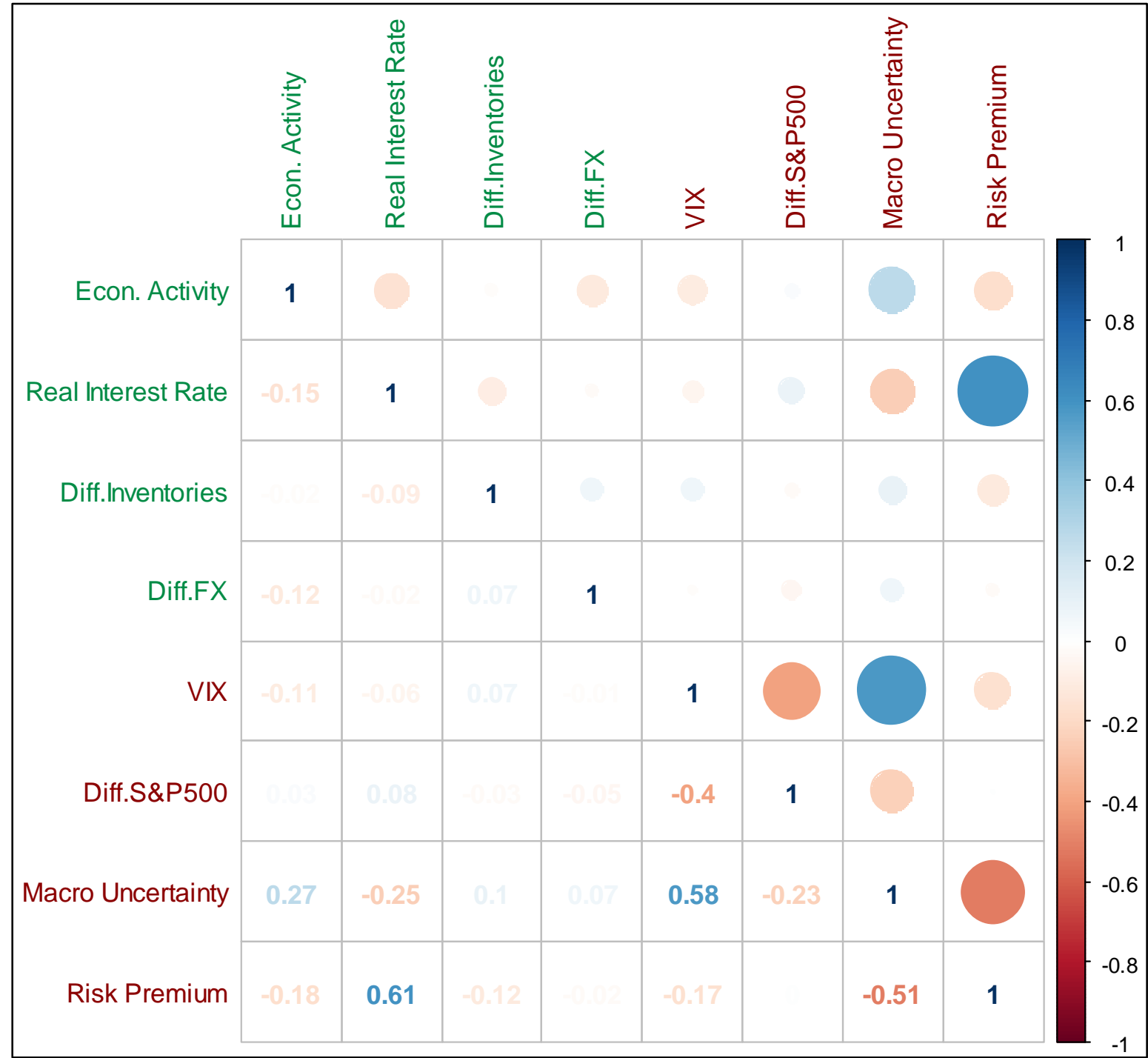

This figure shows the monthly sample correlations for the fundamental economic variables (green axis labels) and financialization variables (red axis labels) from January 1990 to December 2015 (320 obs.). The correlations are close to zero for most variables and only moderate for others, indicating that each variable contains sufficient own variation to justify inclusion into our model. 


\section{Panel A: Relative Importance of Fundamental and Financial Factors}

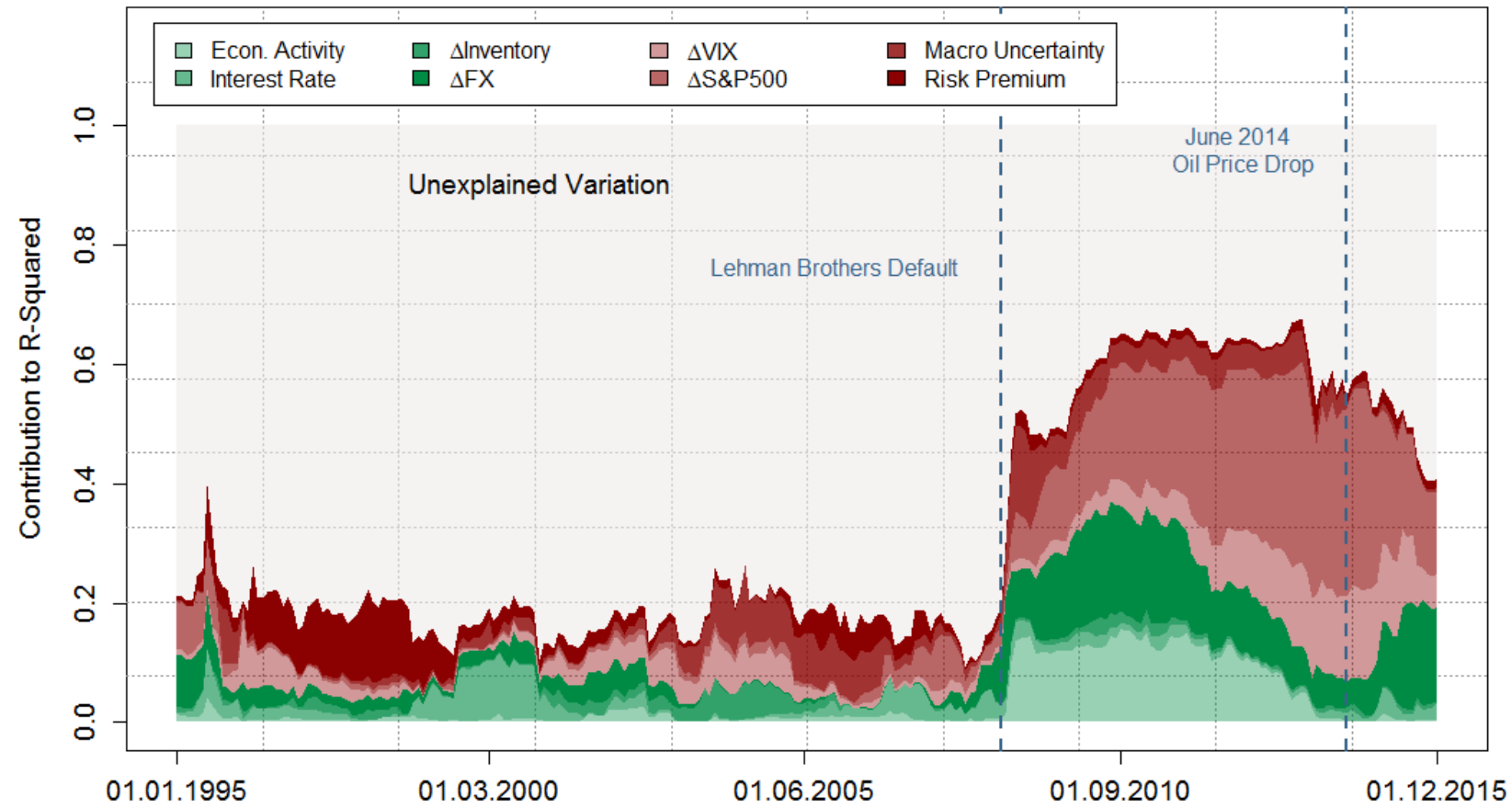

\section{Panel B: Relative Importance Shares in Subsamples}

\section{Pre-Financialization Period}

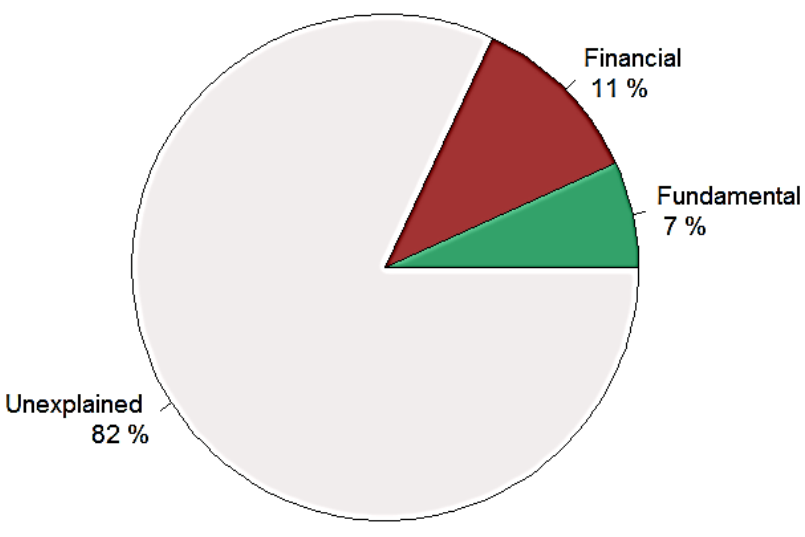

Financialization Period

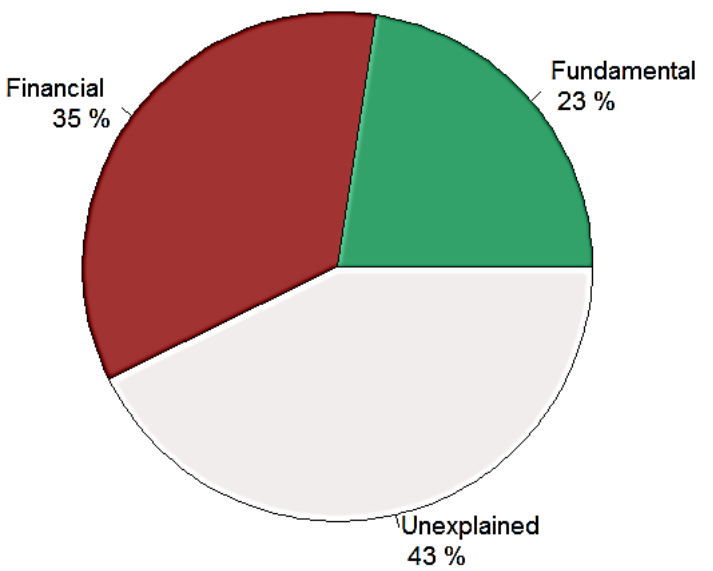

This figure shows the relative importance of economic fundamental and financial variables in explaining the total variation of crude oil returns. Green shaded areas denote the contribution of economic variables to the regression Rsquared. Red shaded areas denote the contribution of financial variables. For a given month, the sum over all shaded areas denotes the overall $\mathrm{R}$-squared of the regression. The remaining area represents the unexplained variation in crude oil returns. 


\section{Panel A: Relative Importance of Fundamental and Financial Factors}

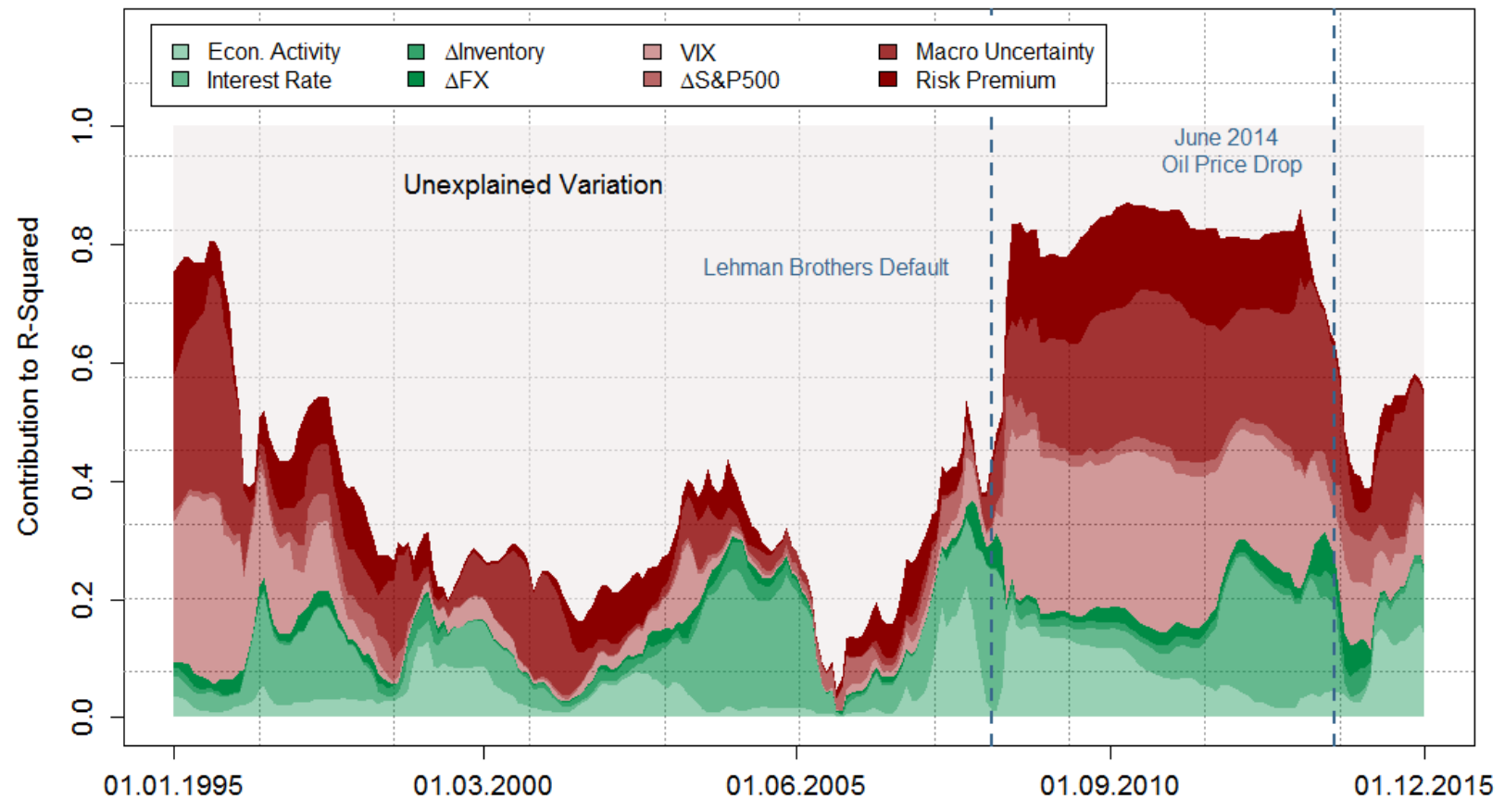

\section{Panel B: Relative Importance Shares in Subsamples}

Pre-Financialization Period

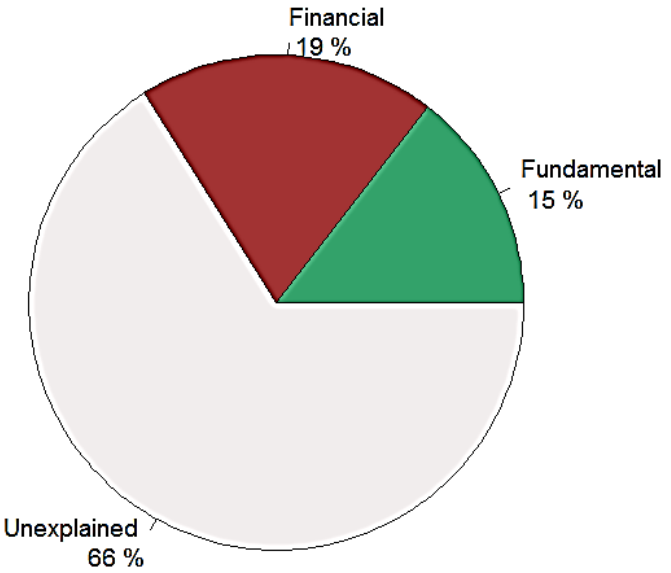

Financialization Period

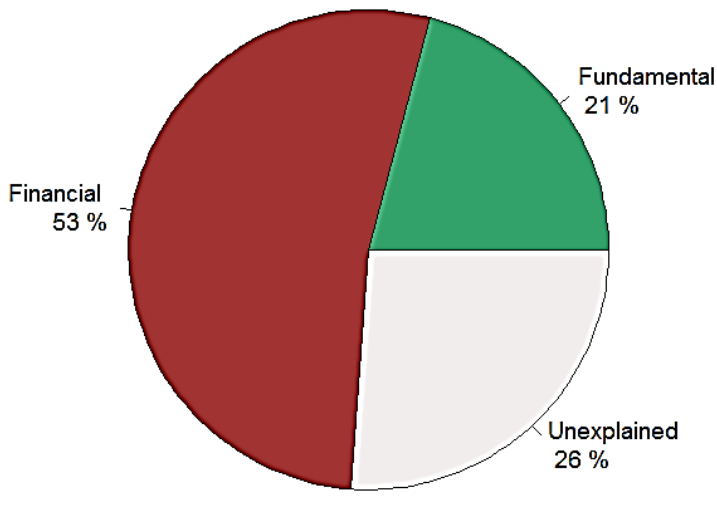

This figure shows the relative importance of economic fundamental and financial variables in explaining the total variation of crude oil volatility. Green shaded areas denote the contribution of economic variables to the regression Rsquared. Red shaded areas denote the contribution of financial variables. For a given month, the sum over all shaded areas denotes the overall R-squared of the regression. The remaining area represents the unexplained variation in oil volatility. The regressions are rolled forward in a 5-year rolling window (60 monthly observations). 


\begin{tabular}{ccc}
\hline Permutation & $\operatorname{var}\left(Y \mid X_{j}, j \in S\right)$ & $\operatorname{var}\left(Y \mid X_{M}, M \in M \cup S\right)$ \\
\hline $\mathbf{1}$ & $\operatorname{var}(Y)$ & $\operatorname{var}\left(Y \mid X_{1}, X_{2}, X_{3}\right)$ \\
$\mathbf{3}$ & $\operatorname{var}(Y)$ & $\operatorname{var}\left(Y \mid X_{1}, X_{3}, X_{2}\right)$ \\
$\mathbf{4}$ & $\operatorname{var}\left(Y \mid X_{2}, X_{3}\right)$ & $\operatorname{var}\left(Y \mid X_{1}, X_{2}, X_{3}\right)$ \\
$\mathbf{5}$ & $\operatorname{var}\left(Y \mid X_{3}, X_{2}\right)$ \\
$\mathbf{6}$ & $\operatorname{var}\left(Y \mid X_{2}, X_{3}\right)$ & $\operatorname{var}\left(Y \mid X_{1}, X_{2}, X_{3}\right)$ \\
& $\operatorname{var}\left(Y \mid X_{3}, X_{2}\right)$ & $\operatorname{var}\left(Y \mid X_{1}, X_{3}, X_{2}\right)$ \\
\hline
\end{tabular}

This Table shows the $p !=6$ permutations for a simple linear regression model with $p=3$ regressors. Note that permutation 1 and 2 lead to the same value. The same holds for permutations 5 and 6 . There are therefore only 4 unique values. The measure $\operatorname{LMG}\left(x_{1}\right)$ denotes the contribution of the variable $x 1$ to the explanatory power of the model and is computed as the average of the difference between column 2 and 3 divided by the total variance $\operatorname{Var}(Y)$ (see Eq.(3)). 